\title{
Challenging Assumptions in Learning Analytics
}

\author{
Shane Dawson, Dragan Gašević and Negin Mirriahi \\ Editors, Journal of Learning Analytics \\ jla.editorial@gmail.com
}

\begin{abstract}
This final issue for 2015 includes a special section of invited papers from the recent Learning Analytics and Knowledge conference (LAK15). The collected papers connect with the conference theme of "Scaling up: Big data to Big Impact" and reflect the emerging trends and future directions of learning analytics research.
\end{abstract}

Keywords: learning analytics, LAK, Society for Learning Analytics Research, bridge building

\section{A MATURE FIELD}

The early stages of learning analytics research tended to focus on identifying predictive models of student academic performance (Dawson, Gašević, Siemens, \& Joksimovic, 2014). Clearly from these early days the research has now well progressed. The numerous presentations at the very successful $5^{\text {th }}$ International Learning Analytics and Knowledge Conference $\left(\right.$ LAK15) ${ }^{1}$, highlighted the significant transition the field has made in moving from broad predictive models to more nuanced insights into student learning progress (Ferguson \& Clow, 2015; Kovanović et al., 2015; Prinsloo \& Slade, 2015; Snow, Allen, Jacovina, Perret, \& McNamara, 2015). However, as noted by the closing panel at LAK15, while there is an abundance of work developing new analytic approaches there remains an absence of research concentrated on developing theory and knowledge. As we continue to explore new methods and approaches in analytics we must also encourage and foster a community of healthy critique. This includes opportunities to explore alternate conceptionalisations and theory related to learning analytics as well as challenging assumptions (Gašević, Dawson, \& Siemens, 2015; Wise \& Shaffer, 2015).

In bemoaning the state of education, Leadbeater and Wong (2010) outlined a set of strategies that could serve to transform schools and learning. A core strategy in this pursuit is for education to be more active, engaging and entrepreneurial that "draws" students deeper into their learning process. Undoubtedly, this is a space where learning analytics has, and will continue to play a significant role. However, the blind pursuit of technologies and user data must be balanced with a deeper critical lens as raised by the LAK15 closing panel. In this context, Leadbeater (2000) argues it is often our perceived knowledge that often prevents us from taking risks. In Leadbeater's terms useful ignorance can serve to prompt new insights and innovation through explorations of research in unchartered domains. This is an important concept for the rapidly growing learning analytics community. As the field grows there is a

\footnotetext{
${ }^{1}$ http://lak15.solaresearch.org/schedule
} 
concern that we stop challenging the very assumptions that we are now building LA research upon. When we take for granted what "effective analytics" are - we are less inclined to move away from these "certainties" and will continue to propagate the assumptions they are founded on. It is time to stop, reflect and revisit the methodological and theoretical foundations the field is establishing, and perhaps, taking for granted. As the $6^{\text {th }}$ annual LAK conference approaches, we must continue strive to provide opportunities to bring in new voices from diverse disciplines into dialogue and experiment with alternate approaches that challenge the security of our often tightly held beliefs.

\section{THIS ISSUE}

This issue features a special section that draws on invited papers from the recent LAK15 conference. All accepted papers were extensions of the conference proceedings and underwent further peer review before final acceptance. The papers illustrate the extension of learning analytics from the once staple diet of LMS data to classroom, physiological and MOOC data. The papers illustrate how some of the fundamental assumptions learning analytics are built on can be challenged (e.g., whether time online estimations are accurate). More importantly, challenging these assumptions can have significant implications on the validity of results and the longer-term credibility of the field as a whole. The guest editors Agathe Merceron, Paulo Blikstein and George Siemens selected those papers that not only reflected the conference theme of "Scaling up: Big Data to Big Impact" but also the diversity of research presented. The special section editorial identifies the emerging trends in learning analytics and the directions of the field based on an analysis of the LAK15 conference proceedings. The special section papers explore a range of analytic approaches and issues including: a) the use of LATUX workflow to develop intuitive visualisations to aid instructor feedback and interventions; $b$ ) the merging of NLP and entropy methods; c) a replication study to verify clusters of student behaviours in MOOCs, and d) a review of how different calculations and definitions of time online or on-task can influence results.

The final issue for 2015 concludes with a paper by Knight and Littleton (this issue). In exploring productive dialogue as a means to enhance education outcomes the authors seek to blend analytics or computational models with the learning sciences. As the authors argue, there is a lack of operational constructs that can aid researchers in undertaking analysis of what constitutes productive dialogue.

We hope you enjoy the following papers and we encourage you to reflect on the extent to which these papers and some of your work challenge and/or are challenged by existing theoretical foundations. Do not be discouraged if you encounter and experience a disconnection between your work and the current dogma. This is a much-needed space for reflection and consideration and an indicator that you are extending those research boundaries that are so important for developing the field. As learning analytics research evolves, we can expect to see the introduction of new theories and a revision to existing theory. We very much look forward to your continued research submissions that are tackling the key issues that are essential for the maturation and growth of the field. 


\section{REFERENCES}

Dawson, S., Gašević, D., Siemens, G., \& Joksimovic, S. (2014). Current state and future trends: A citation network analysis of the learning analytics field. Proceedings of the Fourth International Conference on Learning Analytics and Knowledge (LAK'14), 231-240. http://dx.doi.org/10.1145/2567574.2567585

Ferguson, R., \& Clow, D. (2015). Examining engagement: analysing learner subpopulations in massive open online courses (MOOCs). Proceedings of the Fifth International Conference on Learning Analytics and Knowledge (LAK'15), 51-58. http://dx.doi.org/10.1145/2723576.2723606

Gašević, D., Dawson, S., \& Siemens, G. (2015). Let's not forget: Learning analytics are about learning. TechTrends, 59(1), 64-71. http://dx.doi/org/10.1007/s11528-014-0822-x

Kovanović, V., Gašević, D., Dawson, S., Joksimović, S., Baker, R. S., \& Hatala, M. (2015). Penetrating the black box of time-on-task estimation. Proceedings of the Fifth International Conference on Learning Analytics and Knowledge (LAK'15), 184-193.

http://dx.doi.org/10.1145/2723576.2723623

Leadbeater, C (2000). Living on thin air: The new economy. New York: Viking

Leadbeater, C., \& Wong, A. (2010). Learning from the extremes. San Jose, CA: Cisco Systems.

Prinsloo, P., \& Slade, S. (2015). Student privacy self-management: implications for learning analytics. Proceedings of the Fifth International Conference on Learning Analytics And Knowledge (LAK '15), 83-92. http://dx.doi.org/10.1145/2723576.2723585

Snow, E. L., Allen, L. K., Jacovina, M. E., Perret, C. A., \& McNamara, D. S. (2015). You've got style: detecting writing flexibility across time. Proceedings of the Fifth International Conference on Learning Analytics and Knowledge (LAK'15), 194-202. http://dx.doi.org/10.1145/2723576.2723592

Wise, A. F., \& Shaffer, D. W. (2015). Why theory matters more than ever in the age of big data. Journal of Learning Analytics, 2(2), 5-13. http://dx.doi.org/10.18608/jla.2015.22.2 